\title{
Prevalence of Uterine Fibroids in Women in Eastern Siberia: A Cross-Sectional Study
}

\author{
Alina V. Atalyan, PhD*; Larisa V. Suturina, PhD, ScD; Iana G. Nadeliaeva, PhD; \\ Liudmila M. Lazareva, PhD; Eldar M. Sharifulin, PhD Student; \\ Irina N. Danusevich, $\mathrm{PhD}, \mathrm{ScD}$ \\ Scientific Centre for Family Health and Human Reproduction Problems \\ Irkutsk, the Russian Federation
}

\begin{abstract}
The objective of this study was to determine uterine fibroids (UF) prevalence in the unselected (medically unbiased) female population in the Eastern Siberia region, Russia, and to evaluate the significant risk factors.

Methods and Results: The study included 2389 women aged from 18 to 80 yrs (mean age of $42.8 \pm 11.9$ yrs). Subjects were evaluated consecutively by means of questionnaires, anthropometry, vital signs, gynecological examination, and pelvic ultrasound. We demonstrated $26.41 \%$ UF prevalence in the unselected female population from Eastern Siberia. We found that the single nodules predominate among all fibroids, with the types $3-5$ and the size of either $\leq 1 \mathrm{~cm}$ or $\geq 4 \mathrm{~cm}$ as the most frequent variants. Our study confirmed that the prevalence of fibroids increases with age. The incidence of fibroids is significantly lower in women with the age at menarche of 15 years. We also have found that a BMI of more than $25 \mathrm{~kg} / \mathrm{m}^{2}$, more than 4 pregnancies, and late menopause are risk factors for the development of fibroids.(International Journal of Biomedicine. 2021;11(4):515-518.)
\end{abstract}

Key Words: uterine fibroid $\bullet$ epidemiology $\bullet$ risk factors

For citation: Atalyan AV, Suturina LV, Nadeliaeva IG, Lazareva LM, Sharifulin EM, Danusevich IN. Prevalence of Uterine Fibroids in Women in Eastern Siberia: A Cross-Sectional Study. International Journal of Biomedicine. 2021;11(4):515-518. doi:10.21103/Article11(4)_OA18

\section{Introduction}

The most common neoplasms affecting women's health are uterine fibroids (UFs), which can cause significant morbidity and may adversely impact fertility. ${ }^{(1-10)}$ Currently, only limited data are available concerning the prevalence and clinical issues of UFs in Russia. ${ }^{(11,12)}$

The most relevant studies on the risk of UFs consider age, race, endocrine disruptors, obesity, and lifestyle, as well as genetic, reproductive, and hormonal factors, as significant predictors. Nevertheless, more studies are needed to further understand UF biology and risk factors to clarify the etiopathogenesis of this disease. ${ }^{(1,13-15)}$

*Corresponding author: Alina V. Atalyan, PhD. Scientific Centre for Family Health and Human Reproduction Problems, Irkutsk, the Russian Federation.E-mail: atalyan@sbamsr.irk.ru
The objective of this study was to determine UF prevalence in the unselected (medically unbiased) female population in the Eastern Siberia region, Russia, and to evaluate the significant risk factors.

The primary study aim was to collect data concerning the prevalence of UFs in the female population of the Eastern Siberia region, and the type, quantity, and size of the myomas. The secondary study aim was to analyze the association between the patient's age and the type, quantity, and size of UFs, as well as between the frequency of the UFs and BMI, parity, age at menarche, menopause presence and age.

\section{Material and Methods}

We performed a multicenter, institution-based, crosssectional study in Irkutsk Region and the Burjat Republic (Russia) during 2016-2019. The study included 2389 women aged from 18 to $80 \mathrm{yrs}$ (mean age of $42.8 \pm 11.9 \mathrm{yrs}$ ). All 
women were stratified by age groups $(\leq 25,26-30,31-35,36-$ $40,41-45,46-50,51-55,56-60,61-65$, and $\geq 66$ years). The participants for this study were recruited during an obligatory, early, medical employment assessment.

Exclusion criteria were as follows: the subject is not willing to comply with all study procedures and be available for the duration of the study; anything that would place the individual at increased risk or preclude the individual's full compliance with or completion of the study; unwillingness to participate or difficulty understanding the consent processes or the study objectives and requirements; history of hysterectomy, bilateral oophorectomy, endometrial ablation, or uterine artery embolization.

Subjects were evaluated consecutively by means of questionnaires, anthropometry, vital signs, gynecological examination, and pelvic ultrasound. Pelvic ultrasound was performed by 3 experienced specialists with the appropriate intra/inter-observer variations, using Mindray M7 (MINDRAY, China), a transvaginal probe $(5,0-8,0 \mathrm{MHz})$ or transabdominal probe $(2,5-5,0 \mathrm{MHz})$.

The following parameters were evaluated: (1) gynecological history (menarche, parity, live-births, abortions, missed abortions, use of hormonal or other contraceptives, gynecological operations); (2) height and weight, body mass index (BMI); (3) ultrasound measurement of the myomas: location, number, size. The UF volume was determined by the following formula: (length $\times$ width $\times$ height $\times 0.457) / 1000$.

We used the initial data derived from the electronic data capture system REDCap. ${ }^{(16)}$ The data were processed in a manner enabling the evaluation utilizing the statistical software STATISTICA version 12 (StatSoft, USA). The frequencies of categorical variables were compared using Pearson's chi-squared test or Fisher's exact test, when appropriate. A probability value of $P<0.05$ was considered statistically significant.

The study was approved by the Ethics Committee of the Scientific Center for Family Health and Human Reproduction Problems. Written informed consent was obtained from each participant.

\section{Results and Discussion}

The main results of our study population are shown in Table 1. As presented, UFs were found in 631(26.41\%) of the total 2389 women included in the present study.

In the majority of patients with fibroids $(57.9 \%)$, ultrasound examination revealed only one single nodule, $19.1 \%$ had 2 fibroids, $11.5 \%$ had 3, and the same number (11.5\%) had 4 or more (Fig. 1 ).

In the present study, fibroids were classified according to their type. ${ }^{(17)}$ The nodules types $3-5$ predominated in all age groups (76.2\%), subserous fibroids (types 6-7) were found in $41.4 \%$ and only $6.3 \%$ of cases had submucous (types $0-2$ ) (Fig.2). For the analysis of the size of myomas, the maximum node in the case of multiple myomas was taken into account. An equal number (35\% each) of all fibroids was $<1 \mathrm{~cm}$ and $>4 \mathrm{~cm} ; 14.5 \%$ of the nodules were from $1 \mathrm{~cm}$ to $2 \mathrm{~cm}, 7.9 \%$ from $2 \mathrm{~cm}$ to $3 \mathrm{~cm}$, and $7.1 \%$, from $3 \mathrm{~cm}$ to $4 \mathrm{~cm}$ (Fig.3).
Table 1.

Characteristics of the study population

\begin{tabular}{|c|c|c|c|c|c|c|}
\hline & \multirow[b]{2}{*}{ 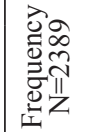 } & \multirow{2}{*}{ 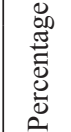 } & \multicolumn{2}{|c|}{ Fibroids } & \multirow[b]{2}{*}{$\begin{array}{c}\mathrm{P}- \\
\text { value }\end{array}$} & \multirow[b]{2}{*}{ OR, $95 \%$ CI } \\
\hline & & & 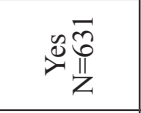 & $\overbrace{z}^{\frac{\infty}{n}} \frac{i}{z}$ & & \\
\hline Age, years & $2389 / 0^{*}$ & & & & $<0.001$ & \\
\hline$\leq 25$ & 161 & 6.74 & $2(1.24)$ & 159 & $<0.001$ & $0.032[0.008 ; 0.129]$ \\
\hline $26-30$ & 235 & 9.84 & $5(2.13)$ & 230 & $<0.001$ & $0.053[0.022 ; 0.129]$ \\
\hline $31-35$ & 349 & 14.61 & $33(9.46)$ & 316 & 0.001 & $0.252[0.174 ; 0.365]$ \\
\hline $36-40$ & 361 & 15.11 & $73(20.22)$ & 288 & 0.004 & $0.668[0.507 ; 0.879]$ \\
\hline $41-45$ & 331 & 13.86 & $104(31.42)$ & 227 & 0.026 & $1.331[1.034 ; 1.713]$ \\
\hline $46-50$ & 292 & 12.22 & $124(42.47)$ & 168 & $<0.001$ & $2.315[1.798 ; 2.980]$ \\
\hline $51-55$ & 246 & 10.30 & $113(45.93)$ & 133 & $<0.001$ & $2.665[2.036 ; 3.490]$ \\
\hline $56-60$ & 242 & 10.13 & $101(41.74)$ & 141 & $<0.001$ & $2.185[1.662 ; 2.873]$ \\
\hline $61-65$ & 103 & 4.31 & $46(44.66)$ & 57 & $<0.001$ & $2.347[1.573 ; 3.499]$ \\
\hline$\geq 66$ & 69 & 2.89 & $30(43.48)$ & 39 & 0.001 & $2.200[1.355 ; 3.573]$ \\
\hline BMI & $2386 / 3^{*}$ & & & & $<0.001$ & \\
\hline$<25$ & 940 & 39.40 & $163(17.34)$ & \begin{tabular}{|c|}
777 \\
\end{tabular} & $<0.001$ & $0.441[0.361 ; 0.540]$ \\
\hline $25-29.9$ & 772 & 32.36 & $236(30.57)$ & 536 & 0.001 & $1.368[1.130 ; 1.655$ \\
\hline $30-34.9$ & 428 & 17.94 & $145(33.88)$ & 283 & $<0.001$ & $1.560[1.246 ; 1.954]$ \\
\hline$\geq 35$ & 246 & 10.31 & $85(34.55)$ & 161 & 0.002 & $1.549[1.170 ; 2.050]$ \\
\hline $\begin{array}{l}\text { Age at } \\
\text { menarche, } \\
\text { years }\end{array}$ & $2385 / 4^{*}$ & & & & 0.045 & \\
\hline$\leq 11$ & 206 & 8.64 & $55(26.70)$ & 151 & 0.934 & $1.014[0.734 ; 1.400]$ \\
\hline 12 & 474 & 19.87 & $134(28.27)$ & 340 & 0.317 & $1.121[0.896 ; 1.404]$ \\
\hline 13 & 661 & 27.71 & $193(29.20)$ & 468 & 0.060 & $1.211[0.992 ; 1.478]$ \\
\hline 14 & 689 & 28.89 & $172(24.96)$ & 517 & 0.292 & $0.897\left[\begin{array}{lll}0.732 & 1.098]\end{array}\right]$ \\
\hline 15 & 208 & 8.72 & $38(18.27)$ & 170 & 0.005 & $0.597[0.415 ; 0.859]$ \\
\hline$\geq 16$ & 147 & 6.16 & $39(26.53)$ & 108 & 0.983 & $1.004[0.688 ; 1.465]$ \\
\hline Menop & $2375 / 14^{*}$ & & & & & \\
\hline yes & 669 & 28.17 & $281(42.00)$ & 388 & $<0.001$ & $2.836[2.337 ; 3.442]$ \\
\hline no & 1706 & 71.83 & $347(20.34)$ & 1359 & & \\
\hline $\begin{array}{l}\text { Age at } \\
\text { menopause, } \\
\text { years }\end{array}$ & $667 / 2 *$ & & & & 0.010 & \\
\hline$\leq 44$ & 85 & 12.74 & $19(22.35)$ & 66 & $<0.001$ & $0.352[0.206 ; 0.601]$ \\
\hline $45-50$ & 197 & 29.54 & $74(37.56)$ & 123 & 0.122 & $0.764[0.543 ; 1.075]$ \\
\hline $50-52$ & 235 & 35.23 & $102(43.40)$ & 133 & 0.623 & $1.084[0.786 ; 1.495]$ \\
\hline $53-55$ & 107 & 16.04 & $60(56.07)$ & 47 & 0.001 & $1.958[1.290 ; 2.974]$ \\
\hline$\geq 56$ & 43 & 6.45 & $26(60.47)$ & 17 & 0.012 & $2.213[1.177 ; 4.163$ \\
\hline Parity & $2386 / 3^{*}$ & & & & & \\
\hline yes & 2058 & 86.25 & $575(27.94)$ & 1483 & $<0.001$ & $1.925[1.418 ; 2.612$ \\
\hline no & 328 & 13.75 & $55(16.77)$ & 273 & & \\
\hline $\begin{array}{l}\text { Parity/ } \\
\text { number }\end{array}$ & 2058 & & & & $<0.001$ & \\
\hline 1 & 321 & 15.60 & $62(19.31)$ & 259 & 0.002 & $0.631[0.470 ; 0.846]$ \\
\hline 2 & 363 & 17.64 & $91(25.07)$ & 272 & 0.531 & $0.921[0.712 ; 1.191]$ \\
\hline 3 & 346 & 16.81 & $79(22.83)$ & 267 & 0.103 & $0.800[0.611 ; 1.047]$ \\
\hline 4 & 281 & 13.65 & $68(24.20)$ & 213 & 0.372 & $0.877[0.656 ; 1.171]$ \\
\hline 5 & 242 & 11.76 & $83(34.30)$ & 159 & 0.003 & $1.524[1.149 ; 2.022]$ \\
\hline 6 & 173 & 8.41 & $60(34.68)$ & 113 & 0.010 & $1.531[1.103 ; 2.123]$ \\
\hline 7 & 108 & 5.25 & $39(36.11)$ & 69 & 0.019 & $1.613[1.078 ; 2.416]$ \\
\hline$\geq 8$ & 224 & 10.88 & $93(41.52)$ & 131 & $<0.001$ & $2.148[1.619 ; 2.851]$ \\
\hline Live-births & 2058 & & & & & \\
\hline yes & 1978 & 96.11 & $561(28.36)$ & 1417 & 0.034 & $0.536[0.299 ; 0.962]$ \\
\hline no & 80 & 3.89 & $14(17.50)$ & 66 & & \\
\hline $\begin{array}{l}\text { Live-births/ } \\
\text { number }\end{array}$ & 1978 & & & & & \\
\hline 1 & 682 & 34.48 & $197(28.89)$ & 485 & 0.708 & $1.040[0.847 ; 1.277]$ \\
\hline 2 & 907 & 45.85 & $275(30.32)$ & 632 & 0,075 & $1.194[0.982 ; 1.453]$ \\
\hline 3 & 333 & 16.84 & $75(22.52)$ & 258 & 0.009 & $0.693[0.525 ; 0.916]$ \\
\hline$\geq 4$ & 56 & 2.83 & $14(25.00)$ & 42 & 0.571 & $0.838[0.454 ; 1.547]$ \\
\hline abortions & $2051 / 7^{*}$ & & & & & \\
\hline yes & 1397 & 68.11 & $448(32.07)$ & 949 & $<0.001$ & $1.978[1.580 ; 2.476]$ \\
\hline no & 654 & 31.89 & $126(19.27)$ & 528 & & \\
\hline $\begin{array}{l}\text { abortions/ } \\
\text { number }\end{array}$ & 1397 & & & & $<0.001$ & \\
\hline 1 & 434 & 31.07 & $111(25.58)$ & 323 & 0.001 & $0.638[0.496 ; 0.822]$ \\
\hline 2 & 361 & 25.84 & $102(28.25)$ & 259 & 0.071 & $0.785[0.604 ; 1.022]$ \\
\hline 3 & 225 & 16.11 & $79(35.11)$ & 146 & 0.286 & $1.178[0.872 ; 1.590]$ \\
\hline 4 & 126 & 9.02 & $46(36.51)$ & 80 & 0.263 & $1.243[0.849 ; 1.820]$ \\
\hline$\geq 5$ & 251 & 17.97 & $110(43.82)$ & 141 & $<0.001$ & $1.865[1.410 ; 2.467]$ \\
\hline $\begin{array}{l}\text { Missed } \\
\text { abortion }\end{array}$ & $2049 / 10^{*}$ & & & & & \\
\hline yes & 60 & 2.93 & $16(26.67)$ & 44 & 0.814 & $0.933[0.522 ; 1.666]$ \\
\hline no & 1989 & 97.07 & $558(28.05)$ & 1431 & & \\
\hline
\end{tabular}




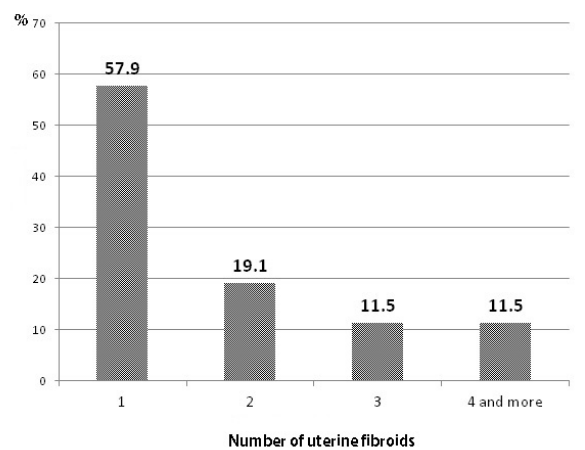

Fig. 1. Number of UFs per patient $(n=631)$.

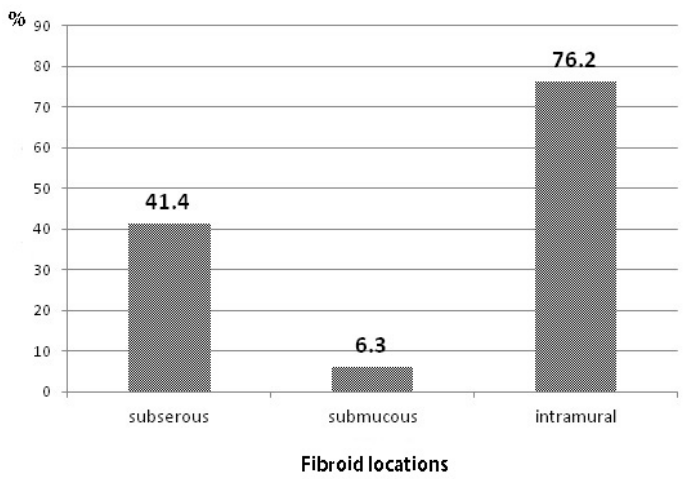

Fig. 2. Fibroid locations in all age groups $(n=782)$.

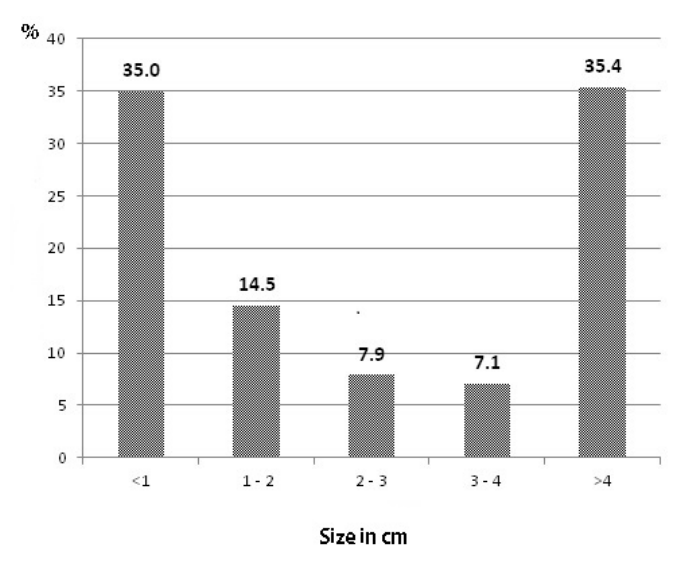

Fig. 3. Size of UFs in all age groups $(n=631)$.

With increasing age, the prevalence of uterine myomas rose from $1.24 \%$ ( $18-25$ years) to $45.93 \%$ (51-55 years). The prevalence of fibroids at the age of 56-60 years was comparable to those at the age of 46-50 years and remained high in the older age groups of 61-65 years and over. The risk estimates were as follows: the age of $\leq 40$ years was associated with a significant decrease in UF risk, whereas the age $\geq 41$ years with an increased risk (Table 1).

By the age of 36-40 years, the number of multiple nodules increased statistically significantly and then remained stable, while the proportion of women with single UF tended to decrease by $41-45$ years (Fig.4).

When analyzing the impact of BMI on the UF prevalence, we found that OR for UF was lower in slim women and higher in women with $\mathrm{BMI} \geq 25 \mathrm{~kg} / \mathrm{m}^{2}$.

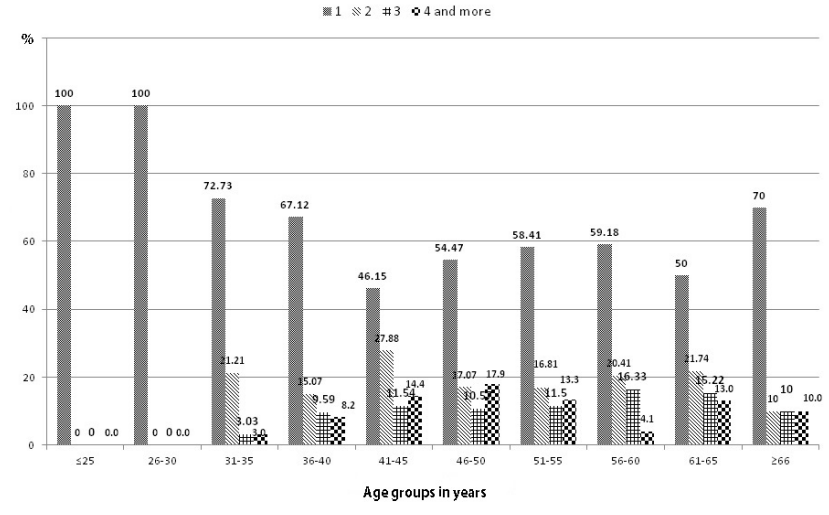

Fig. 4. Number of UFs in study age groups.

The relationship between age at menarche and the UF prevalence has been discussed by different authors. ${ }^{(13)}$ In our study, the mean onset of menarche was between 9 years and 20 years ( $13.3 \pm 1.4$ years). In most cases, no associations were found between the age at the first menstrual cycle and the age of fibroid diagnosis. In almost all age groups, except the group with the age of menarche equal to 15 years, the frequency of fibroids was similar, and ranged from $24.96 \%$ to $29.20 \%$ for age at menarche of 14 and 13 years, respectively. However, for the menarche age of 15 years, the incidence of fibroids is significantly lower (18.27\%).

Menopausal women have a 2 times higher prevalence of fibroids than women of reproductive age, and the presence of menopause is a significant risk factor for fibroids $(\mathrm{OR}=2.8$ $[2.3 ; 3.4])$. The risk for UF rose significantly in women with the age of menopause at $\geq 53$ years, whereas early menopause ( $\leq 44$ years) was shown as a protective factor. However, both of these effects may be influenced by age as a possible impact factor concerning UF prevalence.

In our study, over $86 \%$ had at least one pregnancy. The prevalence of fibroids among this category of study participants was $27.94 \%$. If there were more than 4 pregnancies, the prevalence of fibroids tended to increase from $34.30 \%$ to $41.52 \%$. In our study, we found that among women with a history of abortions, the frequency of fibroids was significantly higher, as compared to that in women without a history of abortions ( $32 \%$ vs. $19.27 \%)$.

In conclusion, we demonstrated $26.41 \%$ UF prevalence in the unselected female population from Eastern Siberia. We found that the single nodules predominate among all fibroids, with the types $3-5$ and the size of either $\leq 1 \mathrm{~cm}$ or $\geq 4 \mathrm{~cm}$ as the most frequent variants. Our study confirmed that the prevalence of fibroids increases with age. The incidence of fibroids is significantly lower in women with the age at menarche of 15 years. We also have found that a BMI of more than $25 \mathrm{~kg} / \mathrm{m}^{2}$, more than 4 pregnancies, and late menopause are risk factors for the development of fibroids.

\section{Acknowledgments}

This article contains material that has been discussed at the VIII International Research and Practical Conference «FUNDAMENTAL AND APPLIED ASPECTS OF 
REPRODUCTION» (December 2021, Irkutsk, Russia). The author thanks all researchers who participated in the oral discussion.

\section{Competing Interests} interests.

The authors declare that they have no competing

\section{References}

1. Ahrendt HJ, Tylkoski H, Rabe T, Szczes A, Friedrich C, Roehl FW, Kitay A, Roemer T, Foth D. Prevalence of uterine myomas in women in Germany: data of an epidemiological study. Arch Gynecol Obstet. 2016 Jun;293(6):1243-53. doi: 10.1007/s00404-015-3930-8.

2. Drayer SM, Catherino WH. Prevalence, morbidity, and current medical management of uterine leiomyomas. Int $\mathrm{J}$ Gynaecol Obstet. 2015 Nov;131(2):117-22. doi: 10.1016/j. ijgo.2015.04.051.

3. Giuliani E, As-Sanie S, Marsh EE. Epidemiology and management of uterine fibroids. Int J Gynaecol Obstet. 2020 Apr;149(1):3-9. doi: 10.1002/ijgo.13102.

4. Suturina L, Lizneva D, Lazareva L, Negative association between PCOS and risk of uterine leiyomyomas in Caucasian infertile women. Reprod Sci 2016; 23: 51A-344A.

5. Laughlin SK, Baird DD, Savitz DA, Herring AH, Hartmann KE. Prevalence of uterine leiomyomas in the first trimester of pregnancy: an ultrasound-screening study. Obstet Gynecol. 2009 Mar;113(3):630-635. doi: 10.1097/ AOG.0b013e318197bbaf.

6. Marsh EE, Al-Hendy A, Kappus D, Galitsky A, Stewart EA, Kerolous M. Burden, Prevalence, and Treatment of Uterine Fibroids: A Survey of U.S. Women. J Womens Health (Larchmt). 2018 Nov;27(11):1359-1367. doi: 10.1089/ jwh.2018.7076.

7. Martín-Merino E, Wallander MA, Andersson S, SorianoGabarró M, Rodríguez LA. The reporting and diagnosis of uterine fibroids in the UK: an observational study. BMC Womens Health. 2016 Jul 25;16:45. doi: 10.1186/s12905-0160320-8.
8. Sparic R, Mirkovic L, Malvasi A, Tinelli A. Epidemiology of Uterine Myomas: A Review. Int J Fertil Steril. 2016 JanMar;9(4):424-35. doi: 10.22074/ijfs.2015.4599.

9. Stewart EA, Cookson CL, Gandolfo RA, Schulze-Rath R. Epidemiology of uterine fibroids: a systematic review. BJOG. 2017 Sep;124(10):1501-1512. doi: 10.1111/1471-0528.14640. 10. Styer AK, Rueda BR. The Epidemiology and Genetics of Uterine Leiomyoma. Best Pract Res Clin Obstet Gynaecol. 2016 Jul;34:3-12. doi: 10.1016/j.bpobgyn.2015.11.018.

11. Suturina LV, Sklyar NV, Labygina AV, Kovalenko II, Ilyin VP, Sholokhov LF. Hormonal and metabolic markers of disordered reproductive function in females with uterine myoma. Doctor.ru. 2009;50:18-21.

12. Tsyrenov TB, Darzhayev Z, Suturina LV, Labygina AV, Pavlova VP, et al.. Hormone-dependent gynecological diseases in infertile women from main ethnic groups of Buryat Republic. Acta Biomedica Scientifica. 2013; 4(92): 74-76. 'Article in Russian].

13. Pavone D, Clemenza S, Sorbi F, Fambrini M, Petraglia F. Epidemiology and Risk Factors of Uterine Fibroids. Best Pract Res Clin Obstet Gynaecol. 2018 Jan;46:3-11. doi: 10.1016/j. bpobgyn.2017.09.004.

14. Velez Edwards DR, Baird DD, Hartmann KE. Association of age at menarche with increasing number of fibroids in a cohort of women who underwent standardized ultrasound assessment. Am J Epidemiol. 2013 Aug 1;178(3):426-33. doi: 10.1093/aje/kws585.

15. Wise LA, Laughlin-Tommaso SK. Epidemiology of Uterine Fibroids: From Menarche to Menopause. Clin Obstet Gynecol. 2016 Mar;59(1):2-24. doi: 10.1097/ GRF.0000000000000164.

16. Atalyan AV, Kolesnikova LI, Kolesnikov SI, Grjibovski AM and Suturina LV. Research electronic data capture (redcap) for building and managing databases for populationbased biomedical studies. Human Ecology 2019;(2):52-59. [Article in Russian[.

17. Munro MG, Critchley HO, Broder MS, Fraser IS; FIGO Working Group on Menstrual Disorders. FIGO classification system (PALM-COEIN) for causes of abnormal uterine bleeding in nongravid women of reproductive age. Int $\mathrm{J}$ Gynaecol Obstet. 2011 Apr;113(1):3-13. doi: 10.1016/j. ijgo.2010.11.011. 